\title{
Prácticas de laboratorio interdisciplinares de alto nivel científico con alumnos de diferentes grados universitarios guiados por WebQuest AICLE
}

\author{
Ángel Serrano-Aroca ${ }^{a}$, Belén Frigols ${ }^{a}$ Miguel Martía $^{\text {Sofía }}$ Ingresa-Capaccionia ${ }^{\mathbf{y}}$ \\ Victoria Moreno-Manzano ${ }^{\mathbf{a}, \mathbf{b}}$ \\ ${ }^{a}$ Facultad de Veterinaria y Ciencias Experimentales, Universidad Católica de Valencia San Vicente \\ Mártir, 46001 Valencia, España, baboratorio de Regeneración tisular y neuronal, Centro de \\ investigación Príncipe Felipe, 46012 Valencia, España.
}

\begin{abstract}
Collaboration between experts from different scientific areas is becoming more and more important. Thus, in this work, transversal laboratory sessions have been carried out by students from four different university bachelor's degrees in the area of biomedicine: Biotechnology, Marine Sciences, Veterinary, Dentistry and a degree taught in English: Dentistry. The subjects that participated in the study were: bioreactors, cell cultures, marine microbiology, veterinary microbiology and dentistry microbiology. Working teams addressing a scientific topic such as chemical synthesis and $3 D$ printing of biomaterials, their antimicrobial characterization by three complementary methods (diffusion in agar, contact and biofilm formation in bioreactor) and repopulation by adult stem cell culture. A WebQuest was designed with the instructions, virtual laboratory and laboratory sessions guides in digital format. In order to carry out a Content and Language Integrated Learning (CLIL), the WebQuest was designed in English and the participants made a presentation in English at the end of this experience. The laboratory sessions were carried out in the laboratories of the Catholic University of Valencia and in the Principe Felipe Research Center. This procedure was evaluated through a questionnaire of 14 questions, and by means of two rubrics used for the reports and expositions.
\end{abstract}

Keywords: WebQuest, CLIL, STSE, interdisciplinary team work, bachelor studies, laboratory sessions, virtual laboratory.

\section{Resumen}

Cada vez resulta más importante la colaboración entre expertos de diferentes áreas cientificas multidisciplinares. En este trabajo, se han realizado prácticas de laboratorio agrupando alumnos de cuatro grados universitarios del área de biomedicina: Biotecnología, Ciencias del Mar, Veterinaria, Odontología y un grado impartido en inglés: Dentistry. Las asignaturas, que participaron en el estudio fueron: Biorreactores, Cultivos Celulares, Microbiología Marina, Microbiología Veterinaria, Microbiología de Odontología y Microbiology de Dentistry. Se abordó el tema de las síntesis química y por impresión $3 D$ de 
Prácticas de laboratorio interdisciplinares de alto nivel cientifico con alumnos de diferentes grados universitarios guiados por WebQuest AICLE

biomateriales, su caracterización antimicrobiana por tres métodos complementarios (difusión en agar, contacto y formación de biofilm en biorreactor) y repoblación por cultivo con células madre adultas. Se diseñó una WebQuest con las instrucciones, laboratorio virtual y guías de prácticas en formato digital. Con motivo de llevar a cabo un Aprendizaje Integrado de Contenido y de Lenguas Extranjeras (AICLE), la WebQuest fue diseñada en inglés y los participantes realizaron una exposición en inglés al finalizar la experiencia. Las prácticas fueron realizadas en los laboratorios de la Universidad Católica de Valencia y en el Centro de Investigación Príncipe Felipe. Este procedimiento fue evaluado mediante un cuestionario de 14 preguntas, y mediante dos rúbricas para las memorias y exposiciones.

Palabras clave: WebQuest, AICLE, trabajo interdisciplinar, grados universitarios, prácticas de laboratorio, laboratorio virtual.

\section{Introducción}

Hoy en día, el trabajo científico está siendo llevado a cabo cada vez más por equipos de trabajo interdisciplinar donde expertos de varios centros de investigación, que trabajan en áreas científicas totalmente diferentes, colaboran para resolver problemas multidisciplinares (Omodei y col. 2017). La competencia de trabajo en equipo se define como la disposición personal y la colaboración con otros para realizar actividades y lograr objetivos comunes, intercambiando información, asumiendo responsabilidades, resolviendo problemas y contribuyendo al desarrollo colectivo (Torrelles y col. 2011). En la actualidad, dentro del aprendizaje colaborativo destaca el aprendizaje que hace uso de las tecnologías de la información y comunicación, que es una herramienta que consigue que los estudiantes adquirieran competencias digitales de gran utilidad, tanto en entornos universitarios como profesionales (Roberts y col. 2005). Los grandes avances informáticos han conseguido conectar a personas sin barreras temporales ni geográficas (Goodyear y col. 2014). De este modo, cada vez resulta más frecuente que muchos proyectos industriales y de investigación sean desarrollados por equipos multidisciplinares de profesionales localizados en zonas geográficas diferentes, trabajando juntos de forma virtual (Sheppard y col. 2004). Por tanto, es muy importante que los estudiantes universitarios no solamente sean competentes en el área científica de estudio elegido, sino también adquieran experiencia de trabajo online en grupos multidisciplinarios y con miembros de diferentes localidades y países (Hermann y col. 2001, Popov y col. 2014). Los entornos virtuales como complemento de prácticas de laboratorio son utilizados cada vez más porque proporcionan una plataforma de aprendizaje que refuerzan los fundamentos principales de los experimentos. De este modo se ha demostrado que se produce una mejora considerable en el desarrollo de las prácticas de laboratorio y son de gran utilidad para el alumnado (Domingues, 2010; Serrano-Aroca, 2015). Además, la integración de la experimentación real con la simulación virtual por ordenador puede contribuir a un aprendizaje activo más efectivo (Kocijancic, 2004; Jong, 2013).

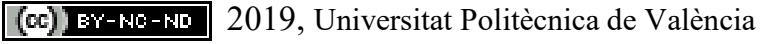




\subsection{WebQuest}

La metodología WebQuest fue inventada en 1995 por Bernie Dodge en la Universidad Estatal de San Diego. Esta herramienta consiste en un formato tipo página web en el cual la mayoría de la información con la que los estudiantes trabajan proviene de la web. Este modelo ha sido de gran utilidad para miles de personas de todo el mundo desde su invención y ha tenido mayor éxito en Brasil, España, China, Australia y Holanda (Dodge, 2007).

Esta metodología permite organizar el proceso de aprendizaje del alumnado (Chalmers, 2003) y se suelen diseñar para que el alumno se centre en utilizar la información en vez de buscarla. Además, esta herramienta resulta de gran utilidad tanto para los alumnos como para el profesorado debido a que proporciona estructura y orientación (Dodge, 2001). La WebQuest permite al alumno construir a partir de información obtenida de Internet (Segers, 2009). Dodge (1997), se refiere a la teoría dimensional de aprendizaje de Marzano, que se basa en la taxonomía de Bloom de los objetivos educativos (Marzano, 1992), con sus raíces en la ciencia cognitiva como la teoría que subyace al concepto de WebQuest. La taxonomía de Bloom de los objetivos educativos describe seis niveles de procesos cognitivos: conocimiento, comprensión, aplicación, análisis, síntesis y evaluación. Las habilidades mentales de orden superior involucran a los últimos tres procesos cognitivos y está asumido que son estimulados por la mayoría de WebQuest (Marzano, 2007). Sin embargo, las actividades relacionadas con la web que apelan solamente a los tres primeros procesos cognitivos se consideran ejercicios web (March, 2004).

\subsection{AICLE}

Actualmente en Europa existe una creciente implementación de una lengua diferente como medio de enseñanza de asignaturas no lingüísticas. Esta metodología de enseñanza se denomina Aprendizaje Integrado de Contenidos y Lenguas Extranjeras (AICLE) o CLIL de sus siglas en inglés y permite el aprendizaje de materias e idiomas al mismo tiempo con el objetivo de la Unión Europea de conseguir que todos los ciudadanos puedan comunicarse en al menos dos lenguas. La resolución del Consejo de 1995 puso de manifiesto la importancia de la mejora de la calidad y la diversificación del aprendizaje y de la enseñanza de las lenguas en los sistemas educativos de la Unión Europea para impartir una enseñanza bilingüe de asignaturas distintas de las lenguas.

Está demostrado que mediante AICLE los alumnos aprenden más y están más motivados que en la enseñanza tradicional de materias específicas (Wolff, 2009). Además, esta metodología potencia la autonomía del alumno (Wolf, 2011) y ofrece muchas ventajas tanto a estudiantes como a docentes, ya que el alumno procesa la lengua extranjera de forma más profunda e intensa y con mayor nivel cognitivo.

La realización de actividades AICLE en estudios superiores universitarios es fundamental, sobre todo en grados científicos donde la mayoría de libros y publicaciones se realizan en inglés. De este modo, con la metodología AICLE se puede conseguir que los estudiantes aprendan contenidos muy importantes del tema abordado y al mismo tiempo competencia lingüística en lengua inglesa aprendiendo vocabulario y expresiones especializadas de su área 
Prácticas de laboratorio interdisciplinares de alto nivel cientifico con alumnos de diferentes grados universitarios guiados por WebQuest AICLE

de conocimiento. La unión de la WebQuest con AICLE permite potenciar la docencia AICLE ya que se establecen pautas precisas e instrumentos para implementar la lengua extranjera de forma adecuada (Fernández Fontecha, 2010; Räsänen, 1996; Hartiala, 2000).

\section{Objetivos}

El objetivo del presente proyecto se enmarca dentro de línea de mejora de adquisición de competencias de carácter transversal. El trabajo de esta competencia es fundamental para la formación de futuros científicos y profesionales que al terminar la carrera van a necesitar cada vez más saber trabajar en entornos multidisciplinares utilizando la lengua inglesa como medio de comunicación. Los objetivos a los que contruirá este proyecto son (i) conseguir una mejora considerable de la competencia de trabajo transversal multidisciplinar de los alumnos participantes e (ii) impulsar el interés por la investigación desde los primeros cursos de los grados universitarios de ciencias.

\section{Desarrollo de la innovación}

\subsection{Participantes}

\subsubsection{Alumnos}

La metodología de este trabajo fue aplicada a 24 estudiantes de la Universidad Católica de Valencia San Vicente Mártir. El proyecto estuvo abierto a cualquier alumno matriculado independientemente de su expediente académico, ya que la selección de los alumnos se realizó mediante sorteo de los alumnos voluntarios inscritos para participar. Estos alumnos fueron de edades comprendidas entre 18 y 22 años. Se formaron cuatro grupos de 6 alumnos con un alumno de cada asignatura participante en el proyecto: Biorreactores de 3er curso de Biotecnología, Cultivos Celulares de 3er curso de Biotecnología, Microbiología Veterinaria de $2^{\circ}$ curso de Veterinaria, Microbiología Marina de $2^{\circ}$ curso de Ciencias del Mar, Microbiología de $1^{\circ}$ de Odontología y Microbiology de $1^{\circ}$ curso de Dentistry.

\subsubsection{Profesores}

Cinco profesores universitarios con diferentes estudios científicos participaron en el proyecto. Tres de los profesores son doctores en Veterinaria especializados en microbiología, una profesora doctora en farmacia especializada en cultivos celulares y un doctor en ingeniería química especializado en biomateriales. El profesor de la asignatura de Biorreactores realizó la parte de la práctica de síntesis química e impresión 3D de los biomateriales y diseño de la WebQuest. El profesor de la asignatura de Microbiología Marina se encargó de la parte de la práctica de estudio de la capacidad antimicrobiana por difusión en agar de los biomateriales. El profesor de la asignatura de Microbiología Veterinaria impartió la parte de estudio de la capacidad antimicrobiana por contacto de los biomateriales. El profesor de la asignatura de Cultivos Celulares realizó la parte de cultivos celulares en los biomateriales y su observación al microscopio confocal. El profesor de la asignatura de 
Microbiología y Microbiology, realizó la parte de estudio de la formación de biofilm en los biomateriales con biorreactor (ver Figura 1). Entre los cinco profesores participantes, se realizaron diversas reuniones en las diferentes fases del proyecto para coordinar las cinco partes de la práctica de laboratorio mencionadas.

Fig. 1. Esquema de la metodología docente implementada.

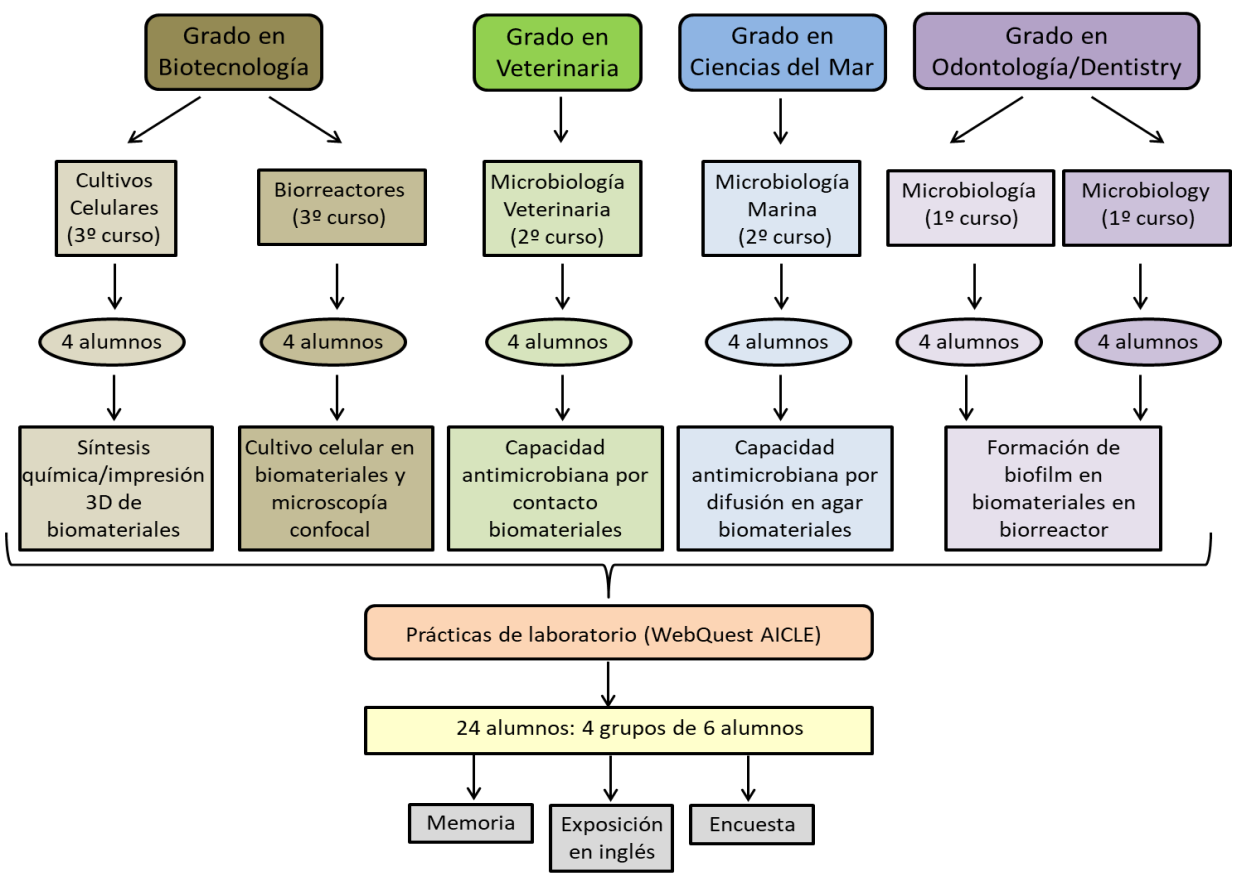

\subsection{Prácticas de laboratorio: trabajo en equipo interdisciplinar.}

Las prácticas de laboratorio se realizaron de forma presencial en los laboratorios de la Facultad de Veterinaria y Ciencias Experimentales de la Universidad Católica de Valencia San Vicente Mártir y en el Laboratorio de Regeneración Tisular y Neuronal del Centro de Investigación Príncipe Felipe. Se realizaron prácticas de laboratorio de alto nivel científico interdisciplinares utilizando tecnologías avanzadas existentes como la impresión 3D, la síntesis de scaffolds con biomateriales de origen natural o el empleo de células madre adultas desde cultivos primarios. Toda esta experiencia científica fue guiada por internet a través de la WebQuest AICLE. En la práctica de laboratorio, los alumnos de la asignatura de Biorreactores prepararon biomateriales avanzados mediante síntesis química y por impresión 3D en el laboratorio y los alumnos de Cultivos Celulares estudiaron las propiedades biológicas de estos materiales en contacto con las células troncales. Los alumnos de Ciencias del Mar estudiaron la capacidad antimicrobiana mediante el método de difusión en agar de estos materiales frente a bacterias importantes como Staphylococcus aureus. Por otro lado, los alumnos de Veterinaria estudiaron las propiedades antimicrobianas de estos biomateriales mediante otra técnica denominada de contacto y los alumnos de Odontología estudiaron las propiedades antimicrobianas de formación de biofilm mediante un biorreactor para bacterias. Por último, todos los alumnos buscaron información en artículos científicos recientes de alto 
impacto, con la ayuda del profesor, para poder proponer aplicaciones de los biomateriales en sus respectivas áreas de estudio. Una vez finalizadas las prácticas, los seis alumnos de cada grupo se reunieron para discutir y elaborar una memoria conjunta que presentaron siguiendo las instrucciones indicadas en la WebQuest. Este trabajo finalizó con la exposición de los resultados y sus potenciales aplicaciones en las diferentes disciplinas asociadas a sus grados, en inglés en una presentación de máximo 2 minutos por alumno (12 minutos en total) por grupo.

\subsection{Aspectos de bioética}

Debido a que la experimentación con animales requiere de la aprobación previa por un comité ético, los alumnos de cada grupo se encargaron de buscar toda la información requerida para solicitar la futura implantación de los biomateriales desarrollados en animales.

\subsection{Evaluación de la metodología docente}

Para poder evaluar esta metodología de enseñanza-aprendizaje, se realizaron encuestas a todos los alumnos participantes en el proyecto y se calificaron las memorias y exposiciones en inglés mediante rúbrica de evaluación para poder disponer de más resultados que permitan cuantificar el nivel de enseñanza y motivación logrado. Estos sistemas de evaluación estuvieron disponibles en la WebQuest desde el comienzo del proyecto para que los alumnos supieran de antemano cómo iban a ser calificadas sus memorias y exposiciones. Las memorias de prácticas en inglés y exposiciones fueron evaluadas por los cinco profesores participantes en el proyecto para determinar una calificación media representativa evaluando por puntos criterios consensuados sobre la calidad, forma y contenido de la memoria escrita (Tabla 1) y de la presentación oral (Tabla 2). Todos los alumnos que participaron en el proyecto de innovación docente recibieron un certificado de participación como reconocimiento de su trabajo realizado.

\subsection{WebQuest con enfoque AICLE}

En la introducción de la WebQuest diseñada (Serrano-Aroca, 2018) se expone una pequeña introducción en inglés a la síntesis de los biomateriales, la ingeniería tisular, el cultivo celular y los tres métodos de caracterización antimicrobiana de biomateriales por difusión en agar, contacto y formación de biofilm en cultivo bacteriano en biorreactor. En el apartado correspondiente a las prácticas de laboratorio a realizar (Laboratory Sessions) se indica la experimentación a realizar con un enlace a los manuales de instrucciones en archivo pdf descargable mediante Tablet, Smartphone u ordenador (Serrano-Aroca, 2018). La WebQuest dispone también de unas prácticas virtuales (Virtual Laboratory), para realizar el alumno en el ordenador desde casa o con un ordenador portátil en la Universidad para completar los conocimientos adquiridos en el laboratorio y potenciar el trabajo autónomo. Esta experiencia virtual (Serrano-Aroca, 2018) aborda en inglés conceptos relativos a material general de laboratorio, manejo del microscopio óptico, impresión 3D, cultivo celular y biofilm 
bacteriano. Además, la WebQuest consta de un penúltimo apartado (Reports\&Presentations) con toda la información al respecto de las exposiciones en inglés a realizar por cada grupo y en cuanto a la elaboración de la memoria indicando claramente su estructura y contenidos que deben contener (Serrano-Aroca, 2018). Finalmente, se indica cómo serán evaluados los alumnos en las memorias y las exposiciones (Serrano-Aroca, 2018) mostrando las dos rúbricas de evaluación (ver tabla 1 y 2 respectivamente), que otorgan un conjunto de criterios y estándares, generalmente relacionados con objetivos de aprendizaje, que se utilizan para evaluar un nivel de desempeño o tarea (Brookhart, 2013).

\subsection{Evaluación}

Para evaluar el conocimiento adquirido por los alumnos se realizó como tarea la de presentar una memoria de prácticas por grupo y una exposición en grupo final en inglés en el Salón de Actos de la Facultad de Veterinaria y Ciencias Experimentales de la Universidad Católica de Valencia San Vicente Mártir. La nota de las memorias y de las exposiciones se determinó mediante dos rúbricas de evaluación que otorgan una calificación total de 0 a 10 (ver tabla 1 y 2 respectivamente). En cuanto a la memoria, se evalúa tanto la calidad del contenido como la calidad de su presentación evaluando cada uno de los indicadores que se indican en la rúbrica.

Tabla 1. Rúbrica de evaluación de las memorias de prácticas.

\begin{tabular}{|c|c|c|c|c|c|}
\hline INDICADOR & Nivel 1 & Nivel 2 & Nivel 3 & Nivel 4 & Puntos \\
\hline EXTENSIÓN & $\begin{array}{c}\text { Extensión } \\
\text { inferior de } \\
\text { la adecuada } \\
\text { del } 50 \% \text { al } \\
100 \% \\
\text { menor. }\end{array}$ & $\begin{array}{c}\text { Extensión } \\
\text { inferior de la } \\
\text { adecuada del } \\
25 \% \text { al } 50 \% \\
\text { menor. }\end{array}$ & $\begin{array}{c}\text { Extensión } \\
\text { inferior de la } \\
\text { adecuada } \\
\text { hasta un } 25 \% \\
\text { menor. }\end{array}$ & $\begin{array}{c}\text { Extensión } \\
\text { adecuada: } \\
\text { memoria de } \\
\text { prácticas } \\
\text { (unas } 23 \\
\text { páginas o } \\
\text { más). del 50\% } \\
\text { al } 100 \% \\
\text { menor }\end{array}$ & $0-2$ \\
\hline $\begin{array}{l}\text { CALIDAD DEL } \\
\text { CONTENIDO }\end{array}$ & $\begin{array}{c}\text { Realiza una } \\
\text { descripción } \\
\text { de las } \\
\text { prácticas } \\
\text { reales } \\
\text { insuficiente } \\
\text { en cuanto a } \\
\text { desarrollo y } \\
\text { contenido. } \\
\text { No incluye } \\
\text { fotografias. } \\
\text { El anexo de } \\
\text { prácticas } \\
\text { virtuales es } \\
\text { muy } \\
\text { deficiente. }\end{array}$ & $\begin{array}{c}\text { Introducción } \\
\text { no muy } \\
\text { adecuadament } \\
\text { e desarrollada. } \\
\text { Describe de } \\
\text { forma pobre } \\
\text { todo el } \\
\text { procedimiento } \\
\text { experimental } \\
\text { realizado de } \\
\text { forma pobre } \\
\text { los resultados } \\
\text { obtenidos en } \\
\text { las prácticas. } \\
\text { Discusión y } \\
\text { redacción de } \\
\text { las } \\
\text { conclusiones } \\
\text { pobre de } \\
\text { acuerdo a las }\end{array}$ & $\begin{array}{c}\text { Introducción } \\
\text { bastante } \\
\text { completa. } \\
\text { Describe } \\
\text { bastante bien } \\
\text { todo el } \\
\text { procedimiento } \\
\text { experimental } \\
\text { realizado, } \\
\text { mostrando de } \\
\text { forma } \\
\text { adecuada y } \\
\text { correcta los } \\
\text { resultados } \\
\text { obtenidos en } \\
\text { las prácticas. } \\
\text { Discusión y } \\
\text { redacción de } \\
\text { las } \\
\text { conclusiones }\end{array}$ & $\begin{array}{c}\text { Introducción } \\
\text { completa, } \\
\text { describe } \\
\text { perfectamente } \\
\text { todo el } \\
\text { procedimiento } \\
\text { experimental } \\
\text { realizado, } \\
\text { mostrando de } \\
\text { forma } \\
\text { excelente y } \\
\text { correcta los } \\
\text { resultados } \\
\text { obtenidos en } \\
\text { las prácticas. } \\
\text { Discusión y } \\
\text { redacción de } \\
\text { las } \\
\text { conclusiones } \\
\text { completa. Se }\end{array}$ & $0-3$ \\
\hline
\end{tabular}




\begin{tabular}{|c|c|c|c|c|c|}
\hline & & $\begin{array}{c}\text { prácticas } \\
\text { realizadas } \\
\text { incluyendo de } \\
0 \text { a } 4 \\
\text { fotografías. El } \\
\text { anexo de } \\
\text { prácticas } \\
\text { virtuales está } \\
\text { regular. }\end{array}$ & $\begin{array}{c}\text { bastante } \\
\text { completa. Se } \\
\text { incluyen de } 5 \\
\text { a } 7 \\
\text { fotografías. El } \\
\text { anexo de } \\
\text { prácticas } \\
\text { virtuales está } \\
\text { bastante bien. }\end{array}$ & $\begin{array}{l}\text { incluyen } 8 \text { o } \\
\text { más } \\
\text { fotografias. El } \\
\text { anexo de las } \\
\text { prácticas } \\
\text { virtuales está } \\
\text { muy bien ( en } \\
\text { caso de } \\
\text { haberse } \\
\text { realizado en } \\
\text { inglés se } \\
\text { valorará } \\
\text { positivamente } \\
\text { subiendo la } \\
\text { nota final } 1 \\
\text { punto). }\end{array}$ & \\
\hline $\begin{array}{c}\text { ESTRUCTURA } \\
\text { Y FORMATO }\end{array}$ & $\begin{array}{c}\text { Documento } \\
\text { sin formato } \\
\text { que no } \\
\text { respeta las } \\
\text { indicaciones } \\
\text { dadas en la } \\
\text { WebQuest. } \\
\text { Aspecto } \\
\text { descuidado. } \\
\text { Uso } \\
\text { continuo de } \\
\text { la primera } \\
\text { persona para } \\
\text { redactar. } \\
\text { Partes del } \\
\text { texto con } \\
\text { redacción } \\
\text { incomprensi } \\
\text { ble. Muchas } \\
\text { faltas de } \\
\text { ortografía y } \\
\text { lenguaje } \\
\text { coloquial. } \\
\text { No incluye } \\
\text { todos los } \\
\text { apartados o } \\
\text { está mal } \\
\text { estructurado }\end{array}$ & $\begin{array}{c}\text { El trabajo } \\
\text { tiene formato } \\
\text { y pocas faltas } \\
\text { de ortografia } \\
\text { o gramática o } \\
\text { puntuación. } \\
\text { Puede } \\
\text { mejorarse el } \\
\text { estilo (utiliza } \\
\text { la primera } \\
\text { persona en } \\
\text { alguna } \\
\text { ocasión). } \\
\text { Incluye todos } \\
\text { los apartados. } \\
\text { Existe } \\
\text { desorden } \\
\text { respecto a la } \\
\text { estructura } \\
\text { propuesta en } \\
\text { la WebQuest. } \\
\text { Hay } \\
\text { coherencia } \\
\text { pero falta de } \\
\text { cohesión entre } \\
\text { los apartados. }\end{array}$ & $\begin{array}{c}\text { Trabajo con } \\
\text { formato y sin } \\
\text { errores, pero } \\
\text { podría } \\
\text { mejorarse el } \\
\text { estilo o la } \\
\text { redacción. Se } \\
\text { adecua la } \\
\text { forma de } \\
\text { expresión } \\
\text { habitual de un } \\
\text { trabajo } \\
\text { académico: } \\
\text { sin lenguaje } \\
\text { coloquial. } \\
\text { Incluye todos } \\
\text { los apartados } \\
\text { indicados en } \\
\text { la WebQuest } \\
\text { y están } \\
\text { desarrollados } \\
\text { pero falta } \\
\text { continuidad } \\
\text { entre ellos. }\end{array}$ & $\begin{array}{l}\text { Formato y } \\
\text { estilo de } \\
\text { redacción } \\
\text { elegante y sin } \\
\text { errores que } \\
\text { facilita la } \\
\text { lectura. } \\
\text { Incluye todos } \\
\text { los apartados } \\
\text { y existe } \\
\text { coherencia y } \\
\text { un desarrollo } \\
\text { lógico entre } \\
\text { ellos. }\end{array}$ & $0-2$ \\
\hline $\begin{array}{c}\text { FIGURAS } \\
\text { NUMERADAS } \\
\text { Y CON TÍTULO } \\
\text { EN EL PIE DE } \\
\text { LAS } \\
\text { FOTOGRAFÍAS }\end{array}$ & $\begin{array}{l}\text { Ninguna } \\
\text { figura se } \\
\text { encuentra } \\
\text { como en el } \\
\text { Nivel } 4 \text { se } \\
\text { indica o } \\
\text { menos o } \\
\text { igual a un } \\
25 \% \text {. }\end{array}$ & $\begin{array}{l}\text { Menos o igual } \\
\text { a un } 50 \% \text { de } \\
\text { las figuras se } \\
\text { encuentran } \\
\text { como en el } \\
\text { Nivel } 4 \text { se } \\
\text { indica. }\end{array}$ & $\begin{array}{c}\text { Menos o igual } \\
\text { a un } 75 \% \text { de } \\
\text { las figuras se } \\
\text { encuentran } \\
\text { como en el } \\
\text { Nivel } 4 \text { se } \\
\text { indica. }\end{array}$ & $\begin{array}{l}\text { Todas o el } \\
75 \% \text { o más de } \\
\text { las figuras se } \\
\text { encuentran } \\
\text { numeradas y } \\
\text { con título en } \\
\text { el pie de las } \\
\text { fotografias. }\end{array}$ & $0-0,5$ \\
\hline $\begin{array}{c}\text { REFERENCIAS } \\
\text { EN TEXTO }\end{array}$ & $\begin{array}{l}\text { No dispone } \\
\text { de } \\
\text { referencias }\end{array}$ & $\begin{array}{c}\text { Dispone de } \\
\text { menos o igual } \\
\text { a un } 50 \% \text { de }\end{array}$ & $\begin{array}{c}\text { Dispone de } \\
\text { menos o igual } \\
\text { a un } 75 \% \text { de }\end{array}$ & $\begin{array}{l}\text { Dispone de } \\
\text { todas las } \\
\text { referencias en }\end{array}$ & $0-0,5$ \\
\hline
\end{tabular}




\begin{tabular}{|c|c|c|c|c|c|}
\hline & $\begin{array}{c}\text { en el texto o } \\
\text { de menos o } \\
\text { igual a un } \\
25 \% .\end{array}$ & $\begin{array}{l}\text { referencias en } \\
\text { el texto. }\end{array}$ & $\begin{array}{l}\text { referencias en } \\
\text { las figuras. }\end{array}$ & $\begin{array}{l}\text { el texto o el } \\
75 \% \text { o más. }\end{array}$ & \\
\hline $\begin{array}{c}\text { REFERENCIAS } \\
\text { EN FIGURAS }\end{array}$ & $\begin{array}{c}\text { No dispone } \\
\text { de } \\
\text { referencias } \\
\text { en las } \\
\text { figuras o de } \\
\text { menos o } \\
\text { igual a un } \\
25 \% \text {. } \\
\end{array}$ & $\begin{array}{l}\text { Dispone de } \\
\text { menos o igual } \\
\text { a un } 50 \% \text { de } \\
\text { referencias en } \\
\text { las figuras. }\end{array}$ & $\begin{array}{l}\text { Dispone de } \\
\text { menos o igual } \\
\text { a un } 75 \% \text { de } \\
\text { referencias en } \\
\text { las figuras. }\end{array}$ & $\begin{array}{l}\text { Dispone de } \\
\text { todas las } \\
\text { referencias en } \\
\text { las figuras o } \\
\text { el 75\% o más. }\end{array}$ & $0-0,5$ \\
\hline $\begin{array}{c}\text { LISTA DE } \\
\text { REFERENCIAS }\end{array}$ & $\begin{array}{l}\text { No dispone } \\
\text { de lista de } \\
\text { referencias } \\
\text { o si dispone } \\
\text { pero con } \\
\text { menos o } \\
\text { igual a un } \\
25 \% \text { de } \\
\text { referencias. }\end{array}$ & $\begin{array}{l}\text { Dispone de } \\
\text { lista de } \\
\text { referencias } \\
\text { con menos o } \\
\text { igual a un } \\
50 \% \text { de } \\
\text { referencias. }\end{array}$ & $\begin{array}{l}\text { Dispone de } \\
\text { lista de } \\
\text { referencias } \\
\text { con menos o } \\
\text { igual a un } \\
70 \% \text { de } \\
\text { referencias. }\end{array}$ & $\begin{array}{l}\text { Dispone de } \\
\text { lista de } \\
\text { referencias } \\
\text { con todas, el } \\
75 \% \text {, o más de } \\
\text { referencias. }\end{array}$ & $0-0,5$ \\
\hline $\begin{array}{c}\text { PÁGINAS } \\
\text { NUMERADAS E } \\
\text { ÍNDICE } \\
\text { AUTOMÁTICO } \\
\text { NUMERADO }\end{array}$ & $\begin{array}{l}\text { No dispone } \\
\text { de páginas } \\
\text { numeradas } \\
\text { ni de índice } \\
\text { automático } \\
\text { numerado. }\end{array}$ & $\begin{array}{c}\text { Dispone de } \\
\text { páginas } \\
\text { numeradas } \\
\text { pero el índice } \\
\text { no es } \\
\text { automático } \\
\text { numerado. }\end{array}$ & - & $\begin{array}{l}\text { Dispone de } \\
\text { páginas } \\
\text { numeradas y } \\
\text { de índice } \\
\text { automático } \\
\text { numerado. }\end{array}$ & 0 a 1 \\
\hline
\end{tabular}

Tabla 2. Rúbrica de evaluación de las exposiciones.

\begin{tabular}{|c|c|c|c|c|c|}
\hline Criterio & $\begin{array}{c}\text { Muy } \\
\text { satisfactorio } \\
\text { (1 punto) } \\
\end{array}$ & $\begin{array}{l}\text { Aceptable } \\
\text { (0.5 puntos) }\end{array}$ & $\begin{array}{l}\text { No aceptable } \\
\text { (0 puntos) }\end{array}$ & $\begin{array}{c}\% \text { de la } \\
\text { nota }\end{array}$ & Puntos \\
\hline $\begin{array}{c}\text { Trabajo en } \\
\text { Equipo } 1\end{array}$ & $\begin{array}{l}\text { Es muy notorio } \\
\text { el trabajo en } \\
\text { equipo realizado } \\
\text { por todos los } \\
\text { integrantes. }\end{array}$ & $\begin{array}{l}\text { Algunos de los } \\
\text { integrantes del } \\
\text { grupo no se les ve } \\
\text { conectividad con } \\
\text { los demás del } \\
\text { grupo. }\end{array}$ & $\begin{array}{l}\text { Los } \\
\text { integrantes del } \\
\text { grupo han } \\
\text { trabajado por } \\
\text { separado cada } \\
\text { tema o } \\
\text { subtema. }\end{array}$ & 10 & \\
\hline $\begin{array}{c}\text { Trabajo en } \\
\text { Equipo } 2\end{array}$ & $\begin{array}{l}\text { El PowerPoint } \\
\text { elaborado es de } \\
\text { muy buena } \\
\text { calidad. }\end{array}$ & $\begin{array}{l}\text { El PowerPoint } \\
\text { elaborado es } \\
\text { regular. }\end{array}$ & $\begin{array}{l}\text { El PowerPoint } \\
\text { elaborado es } \\
\text { de muy baja } \\
\text { calidad. }\end{array}$ & 10 & \\
\hline $\begin{array}{c}\text { Volumen de } \\
\text { voz }\end{array}$ & $\begin{array}{l}\text { El volumen es } \\
\text { lo } \\
\text { suficientemente } \\
\text { alto para ser } \\
\text { escuchado. }\end{array}$ & $\begin{array}{l}\text { El volumen es } \\
\text { cambiante a } \\
\text { medida que } \\
\text { avanza en la } \\
\text { presentación. }\end{array}$ & $\begin{array}{l}\text { El volumen } \\
\text { no es } \\
\text { aceptable, es } \\
\text { muy débil } \\
\text { para ser } \\
\text { escuchado. }\end{array}$ & 10 & \\
\hline $\begin{array}{c}\text { Postura del } \\
\text { cuerpo y } \\
\text { contacto visual }\end{array}$ & $\begin{array}{c}\text { Todos los } \\
\text { miembros } \\
\text { tienen buena }\end{array}$ & $\begin{array}{c}\text { Casi siempre } \\
\text { tienen buena } \\
\text { postura y }\end{array}$ & $\begin{array}{c}\text { Tienen mala } \\
\text { postura y/o no } \\
\text { miran a las }\end{array}$ & 10 & \\
\hline
\end{tabular}




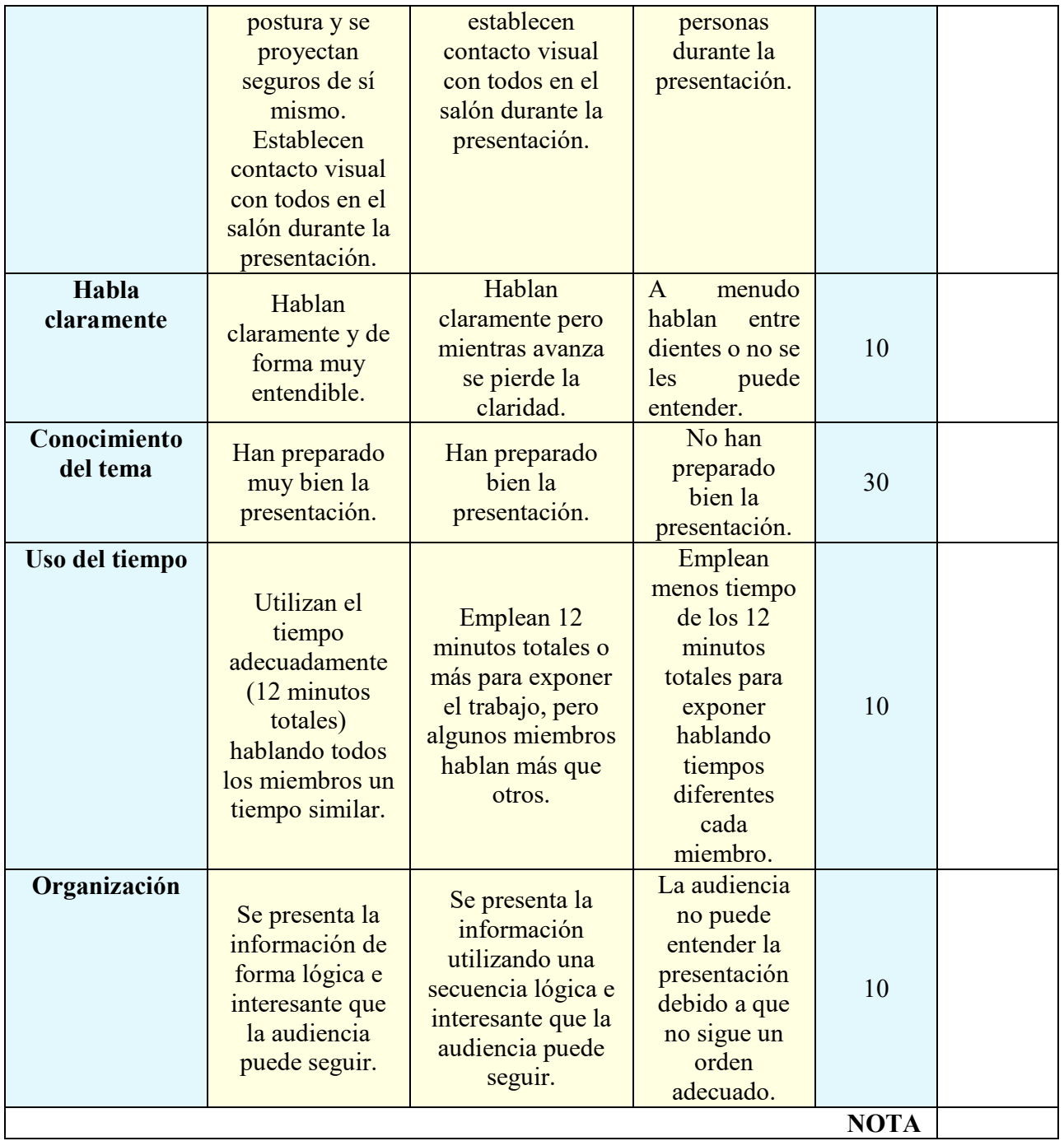

\subsection{Encuesta}

Se ha realizado una encuesta a través de un cuestionario de catorce preguntas formuladas por los cinco profesores universitarios (ver tabla 3 ).

Tabla 3. Encuesta de catorce preguntas sobre la metodología de prácticas para futuros científicos realizada mediante WebQuest-AICLE.

\begin{tabular}{cc}
\hline $\mathbf{N}^{\mathbf{0}}$ & PREGUNTA \\
\hline $\mathbf{1}$ & $\begin{array}{l}\text { La realización de prácticas de laboratorio para futuros científicos unidas a través } \\
\text { de la página web te ha ayudado a entender mejor los conceptos abordados. }\end{array}$ \\
\hline $\mathbf{2}$ & $\begin{array}{l}\text { Te has sentido más motivado al realizar prácticas de laboratorio científicas } \\
\text { formando parte de un equipo de trabajo interdisciplinar. }\end{array}$ \\
\hline
\end{tabular}




\begin{tabular}{|c|c|}
\hline 3 & $\begin{array}{l}\text { Te ha parecido una forma más motivante de realizar prácticas de laboratorio al } \\
\text { ser temas de investigación puntera. }\end{array}$ \\
\hline 4 & La estructura de la actividad te ha parecido lógica y bien organizada. \\
\hline 5 & $\begin{array}{l}\text { El desarrollo de la actividad te ha facilitado la comprensión y aprendizaje de la } \\
\text { materia tratada. }\end{array}$ \\
\hline 6 & $\begin{array}{l}\text { Piensas que tu participación en la búsqueda de artículos científicos en lengua } \\
\text { inglesa para la Preparación de las presentaciones en inglés te ha hecho consciente } \\
\text { de la necesidad de conseguir un gran dominio del inglés en el campo científico. }\end{array}$ \\
\hline 7 & $\begin{array}{l}\text { Te ha resultado útil para tu aprendizaje que el mismo tema se haya abordado } \\
\text { desde distintas perspectivas profesionales. }\end{array}$ \\
\hline 8 & $\begin{array}{l}\text { Crees que has aprendido más con esta metodología WebQuest con prácticas para } \\
\text { futuros científicos con contenidos en inglés que con la llevada a cabo de forma } \\
\text { tradicional. }\end{array}$ \\
\hline 9 & Cómo valoras la parte de prácticas de laboratorio del proyecto (de 1 a 6). \\
\hline 10 & $\begin{array}{l}\text { Cómo valoras la parte de realización de la memoria de prácticas y preparación } \\
\text { de las exposiciones en el equipo interdisciplinar del proyecto (de } 1 \mathrm{a} 6)\end{array}$ \\
\hline 11 & Cómo valoras la parte de las presentaciones en inglés del proyecto (de 1 a 6) \\
\hline 12 & Nivel global de satisfacción del proyecto (de 1 a 6 ) \\
\hline 13 & Recomendarías esta actividad a otros estudiantes de tu grado \\
\hline 14 & $\begin{array}{l}\text { Crees que se deberían realizar más actividades de este tipo entre diferentes } \\
\text { grados de una misma Universidad. }\end{array}$ \\
\hline
\end{tabular}

\section{Resultados}

En este estudio, el tipo de metodología de prácticas de laboratorio, se ha empleado la WebQuest como herramienta de guía del proceso de enseñanza-aprendizaje. Se ha optado por esta herramienta para poder crear mayor interés entre el alumnado y así poder abarcar con las nuevas tecnologías conceptos científicos muy importantes utilizando los recursos avanzados que ofrece hoy en día internet para poder conectar los alumnos participantes de los diferentes grados universitarios.

En las prácticas de laboratorio para futuros científicos AICLE del presente proyecto se trabaja las cuatro habilidades lingüísticas del L2: escuchar, hablar, leer y escribir. De este modo, se deben observar videos en inglés con subtítulos en castellano para trabajar la escucha integrando los conocimientos científicos abordados. Todo esto contribuirá a potenciar el uso del inglés, idioma fundamental en la carrera científica. La lectura se trabaja en los artículos científicos buscados para la elaboración del trabajo final a exponer. El habla se trabaja en las exposiciones finales en inglés. La escritura se trabaja en la elaboración del PowerPoint en inglés de las presentaciones finales. A continuación, en la Tabla 4, se muestran los resultados obtenidos en la evaluación de las memorias de prácticas y exposiciones finales en inglés por los cinco profesores participantes en el proyecto. 
Prácticas de laboratorio interdisciplinares de alto nivel científico con alumnos de diferentes grados universitarios guiados por WebQuest AICLE

Tabla 4. Resultados de la evaluación de las memorias de prácticas y exposiciones en inglés (de 0 a 10). Se indica la media y desviación estándar obtenida de la evaluación de cada grupo por los cinco profesores universitarios participantes en el proyecto.

\begin{tabular}{ccc}
\hline GRUPO & NOTA MEMORIA DE PRÁCTICAS & NOTA EXPOSICIÓN \\
\hline $\mathbf{1}$ & $8.1 \pm 1.2$ & $8.6 \pm 0.5$ \\
\hline $\mathbf{2}$ & $8.8 \pm 0.5$ & $7.6 \pm 0.6$ \\
\hline $\mathbf{3}$ & $8.2 \pm 1.2$ & $7.7 \pm 0.7$ \\
\hline $\mathbf{4}$ & $7.4 \pm 1.2$ & $7.5 \pm 0.3$ \\
\hline
\end{tabular}

Como se puede observar en la Tabla 4, las calificaciones obtenidas en las memorias de prácticas y en las exposiciones en grupo fueron muy positivas, consiguiendo notas altas que denotan la implicación del alumnado en el proyecto de innovación docente. Los resultados obtenidos en las encuestas realizadas a los 24 alumnos participantes se muestran en la Figura 1 .

La experimentación directa donde todos los profesores observaron una gran motivación del alumnado y los resultados de la encuesta ponen de manifiesto una buena aceptación de este modo de realizar prácticas de laboratorio interdisciplinar por parte del alumnado con alumnos de diferentes grados universitarios con medias desde 4.71 hasta 5.43 (ver Figura 2). La satisfacción global del alumnado respecto al proyecto (cuestión 12) es muy alta y la mayoría opina que se deberían realizar más actividades de este tipo entre diferentes grados de una misma universidad (cuestión 14). Además, se ha conseguido que la participación del alumnado en la búsqueda de artículos científicos en lengua inglesa para la preparación de las presentaciones en inglés les haya hecho conscientes de la necesidad de conseguir un gran dominio de la lengua inglesa en el campo científico (cuestión 6) y con una gran satisfacción en cuanto al tipo de prácticas de laboratorio científicas (cuestión 9). 


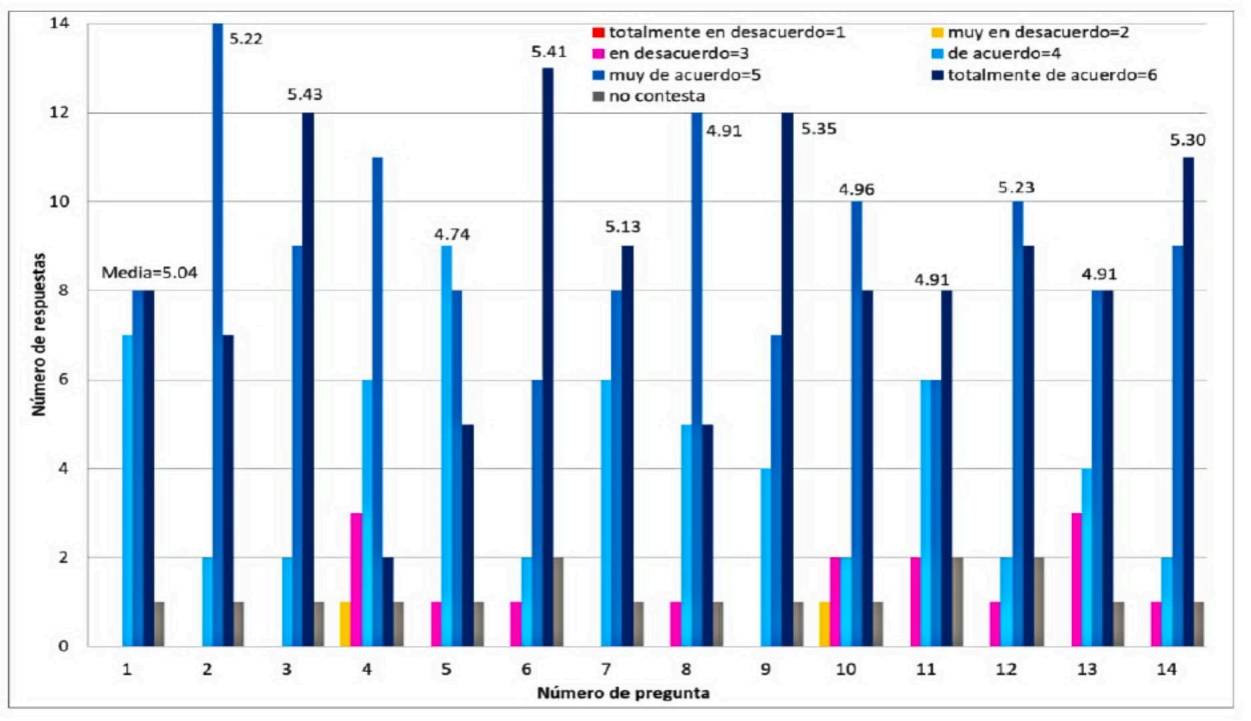

Fig. 2 Resultado de la encuesta de catorce preguntas planteadas sobre las prácticas para futuros científicos guiadas mediante WebQuest con enfoque AICLE a los 24 alumnos participantes. El número de respuestas (calificadas de 1 (totalmente en desacuerdo) a 6 (totalmente de acuerdo)) y el valor medio de estas respuestas para cada pregunta se muestran en esta figura. El color gris representa la opción de no contestar a la pregunta del cuestionario.

Sin embargo, estos resultados también revelan nuestras sospechas iniciales respecto a la dificultad de llevar a cabo tareas interdisciplinares (cuestiones 4 y 5) con un nivel bajo de conocimientos de la lengua inglesa por muchos alumnos que dificulta todavía más el desarrollo de este tipo de actividades no realizadas habitualmente en ninguno de los grados universitarios implicados en el proyecto. De este modo, un gran número de algunos alumnos manifestaron este resultado en los comentarios de la encuesta e indicaron que les supuso un gran esfuerzo al no dominar la lengua inglesa. Por lo tanto, esto manifiesta la necesidad de tomar medidas educativas que potencien el sistema AICLE desde niveles educativos inferiores que consigan facilitar la integración del alumnado universitario al mundo actual científico donde la lengua inglesa es el medio de comunicación dominante.

Tal y como se proponía en los objetivos, el éxito del presente proyecto puede traducirse en una mejora considerable de la competencia de trabajo transversal multidisciplinar de los alumnos participantes en el proyecto. El trabajo de esta competencia es fundamental para la formación de futuros científicos y profesionales, que al terminar la carrera van a necesitar cada vez más saber trabajar en entornos multidisciplinares. Además, se ha conseguido introducir a los alumnos de carreras científicas en la investigación desde los primeros cursos de la carrera. Los resultados del presente proyecto pueden motivar a otros profesores de la universidad a la realización de sesiones de investigación similares interdisciplinares, con la utilización de la lengua inglesa mejorando muchísimo la calidad de la docencia de nuestra universidad e impulsando el interés por la investigación desde los primeros cursos de los grados universitarios. 
Prácticas de laboratorio interdisciplinares de alto nivel científico con alumnos de diferentes grados universitarios guiados por WebQuest AICLE

\section{Conclusiones}

En este estudio se ha aplicado una nueva metodología didáctica que integra todas las ventajas que ofrece por separado la WebQuest y AICLE enfocado a realizar prácticas de laboratorio de alto nivel científico. Los resultados de las encuestas del alumnado han puesto de manifiesto una buena aceptación de este modo de realizar prácticas de laboratorio interdisciplinar con alumnos de diferentes grados universitarios. Además, la satisfacción global respecto al proyecto es excelente y la mayoría de los alumnos cree que se deberían realizar más actividades de este tipo. También se ha conseguido motivar al alumnado y hacerle consciente de la necesidad de dominar el inglés en el campo científico. Sin embargo, estos resultados también revelan la dificultad de llevar a cabo tareas interdisciplinares en inglés debido al bajo nivel lingüístico de la mayoría del alumnado y la necesidad de tomar medidas al respecto.

Debido al éxito de este proyecto, como líneas futuras de trabajo previstas se propone implementar esta metodología potenciando su carácter multidisciplinar incrementando el número de grados participantes. Además, se pretende dar una mayor difusión y carácter científico mediante la realización de un congreso donde se expondrán los resultados obtenidos.

\section{Referencias}

BROOKHART, S. M. (2013) How to Create and Use Rubrics for Formative Assessment and Grading. Alexandria: VA: Association for Supervision and Curriculum Development.

CHALMERS, P. A. (2003) "The role of cognitive theory in human-computer interface". Computers in Human Behaviour, vol.19: issue 5, p. 593-607.

DODGE B. (2007) WebQuest.org. <http://webquest.org/> [Consulta : 22 marzo 2019].

DODGE B. (2001). "FOCUS: Five rules for writing a great WebQuest". Learning and Leading with Technology, 28(8): 6-9.

DODGE, B. (1997). Some Thoughts About WebQuests. $<$ http://webquest.sdsu.edu/about_webquests.html>[Consulta : 22 marzo 2019].

DOMINGUES, L., ROCHA, I., DOURADO, F., ALVES, M., Y FERREIRA, E., C., (2010) "Virtual laboratories in bio(chemical) engineering education“. Education for Chemical Engineers, vol.5, issue 2, p. e22-e27.

FERNANDEZ FONTECHA, A. (2010) “ The CLILQuest: A Type of Language WebQuest for Content and Language Integrated Learning (CLIL) “. Computer Resources for Language Learning, 3: 45-64.

GOODYEAR, P., JONES, C., \& THOMPSON, K. (2014). "Computer-supported collaborative learning: Intructional approaches, group processes and educational designs". Handbook of Research on Educational Communications and Technology. New York: Springer. (pp. 439-451).

HARTIALA, A. K. (2000) "Acquisition of teaching expertise in content and language integrated learning". Doctoral Dissertation. Turku: Painosalama Oy. University of Turku.

HERMANN, F., RUMMEL, N., Y SPADA, H. (2001). "Solving the case together: The challenge of net-based interdisciplinary collaboration". First European Conference on Computer-Supported Collaborative Learning. In P. Dillenbourg, A. Eurelings, \& K. Hakkarainen (Eds.), Proceedings of the first European conference on computer-supported collaborative learning (pp. 293-300). Maastricht: McLuhan Institute. 
JONG, T., LINN, M. C., ZACHARIA, Z. C. (2013) "Physical and Virtual Laboratories in Science and Engineering Education“. $\quad$ Science, Vol.340, no.6130: 305-308, DOI: $10.1126 /$ science. 1230579 .

KOCIJANCIC, S., O'SULLIVAN, C. (2004) "Real or Virtual Laboratories in Science Teaching - is this Actually a Dilemma? "Informatics in Education, vol. 3, No. 2, p. 239-250.

MARCH, T. (2004) " The learning power of WebQuest". Educational Leadership, 61: 42-47.

MARZANO, R. J., Y KENDALL, J. S. (2007). The new taxonomy of educational objectives. Thousand Oaks, CA: Corwin. Corwin press.

MARZANO, R. J. (1992) A different kind of classroom. Teaching with dimensions of learning. Alexandria. VA: Association for Supervision and Curriculum Development.

OMODEI, E., DE DOMENICO, M., Y ARENAS, A. (2017). " Evaluating the impact of interdisciplinary research": A multilayer network approach. Network Science, 5(2): 235-246. DOI:10.1017/nws.2016.15.

POPOV, V., NOROOZI, O., BARRETT, J. B., BIEMANS, H. J. A., TEASLEY, S. D., SLOF, B., Y MULDER, M. (2014). "Perceptions and experiences of, and outcomes for, university students in culturally diversified dyads in a computer-supported collaborative learning environment". Computers in Human Behavior, 32, 186-200.

RÄSÄNEN, A., KAASIK, T., MATHEWS, H. D., ORESIK, H. y SENTOCNIK, S. (1996) “ Profile of teacher qualifications required for bilingual education programmes“. En : Report on workshop 12B, Bilingual education in secondary schools: Learning and teaching non-language subjects through $a$ foreign language. Echternach, Luxemburg: Council of Europe. 277-292.

ROBERTS, T. S. (ED ). (2005). Computer-Supported Collaborative Learning in Higher Education. Hershey, PA: Idea Group Press.

SEGERS E, VERHOEVEN L (2009) “ Learning in a sheltered Internet environment: The use of WebQuest". Learning and Instruction. Vol 19, num 5: 423-432.

SERRANO-AROCA, A. (2015) "Real and Virtual Bioreactor Laboratory Sessions by STSE-CLIL WebQuest", en Education for Chemical Engineers 13, 1-8.

SERRANO-AROCA, A. (2018). Laboratory sessions for future scientists. $<$ http://laboratorysessions.webs.com $>$ [Consulta : 22 marzo 2019]

SHEPPARD, K., DOMINICK, P., \& ARONSON, Z. (2004). " Preparing engineering students for the new business paradigm of international teamwork and global orientation". International Journal of Engineering Education, 20 (3), 475-483.

TORRElles, C., COIDURAS, J., ISUS, S., CARRERA, F., PARIS, G. Y CELA, J. (2011). "Competencia de trabajo en equipo: Definición y categorización. Profesorado." en Revista de Currículum y Formación de Profesorado, 15: 329-344.

WOLFF, DIETER (2009). "Content and Language Integrated Learning“ en Knapp, K-F., Seidelhofer, B. en cooperación con Henry Widdowson (eds.): Handbook of Foreign Language Communication and Learning. Berlín : Mouton de Gruyter.

WOLF, D. (2011). CLIL and Learner Autonomy: relating two educational concepts. Education et Sociétés Plurilingues, 301. $<$ https:/www.unifg.it/sites/default/files/allegatiparagrafo/21-012014/wolff_clil and learner_autonomy.pdf $>$ [Consulta : 22 marzo 2019] 